\title{
PENGARUH PENERAPAN METODE JARIMATIKA TERHADAP KEMAMPUAN BERHITUNG PERKALIAN SISWA KELAS III DI SEKOLAH DASAR NEGERI 15 KOTO BARU DHARMASRAYA
}

\author{
Murni Purnama Sari ${ }^{1}$, Antik Estika Hader ${ }^{2}$, Muhammad Sukron ${ }^{3}$ \\ Universitas Dharmasraya Indonesia
}

Email:murnipurnamasari@gmail.com, An.tique@yahoo.com

\begin{abstract}
ABSTRAK: Penelitian ini dilatar belakangi oleh hasil belajar peserta didik mengalami kesulitan dalam berhitung perkalian, hal ini karena peserta didik mengalami kesulitan dalam menghafal perkalian. Penelitian ini bertujuan untuk mengetahui Pengaruh Penerapan Metode Jarimatika Terhadap Kemampuan Berhitung Perkalian Siwa Kelas III SDN 15 Koto Baru, Dharmasraya.Jenis penelitian ini adalah penelitian Eksperimen Design Pretest-postest one group, dengan pendekatan kuantititatif. Subjek penelitan ini adalah siswa III SDN 15 Koto Baru, Dharmasraya. Pengambilan sampel penelitian ini menggunakan teknik pretest-postest yang terdiri dari 20 pesrta didik. Teknik pengumpulan data dilakukan pre-test dan post-test. Alat pengumpul data berupa soal pilihan ganda yang berjumlah 20 butir soal pre-test maupun post-test Melalui uji validasi,uji reabilitas. Data dianalisa menggunakan uji Normalitas, dan Uji Hipotesis/t-test yang diolah menggunakan SPSS 20. Berdasarkan deskripsi data hasil penelitian data hasil analisis pretest dan postest, dengan menggunakan uji Paired Sample tes menunjukkan nilai signifikasi 0,000<0,05 maka hasil uji Paired sample tes dapat disimpulkan bahwa $\mathrm{H}_{0}$ ditolak dan $\mathrm{H}_{\mathrm{a}}$ diterima. Dengan diterimanya $\mathrm{H}_{\mathrm{a}}$ pada pengujian hipotesis tersebut, maka dapat disimpulkan bahwa penelitian ini dapat menguji kebenaran hipotesis yaitu terhadap peningkatan kemampuan dalam perkalian anatara sebelum dan sesudah diterapkannya metode jarimatika pada kelas III SDN 15 Koto Baru.
\end{abstract}

Kata Kunci: Eksperimen, Jarimatika, Perkalian

\begin{abstract}
This research is motivated by the learning outcomes of students having difficulty in counting multiplication, this is because students have difficulty in memorizing multiplication. This study aims to determine the effect of the application of the Jarimatika Method on the Multiplication Ability of Class III Students at SDN 15 Koto Baru, Dharmasraya. This type of research is a one-group pretest-posttest design experimental study, with a quantitative approach. The subject of this research is the third student of SDN 15 Koto Baru, Dharmasraya. Sampling in this study used a pretest-posttest technique consisting of 20 students. Data collection techniques were carried out pre-test and post-test. The data collection tool is in the form of multiple choice questions, totaling 20 items for pre-test and post-test. Through validation tests, reliability tests. The data were analyzed using the Normality test, and the Hypothesis Test/t-test which was processed using SPSS 20. Based on the description of the research data, the results of the pretest and posttest analysis, using the Paired Sample test, showing a significance value of 0.000 0.05, the results of the Paired sample test can be concluded that HO is rejected and Ha is accepted. With the acceptance of Ha in testing the hypothesis, it can be concluded that this study can test the truth of the hypothesis, namely the increase in ability in multiplication between before and after the application of the Jarimatika method in class III SDN 15 Koto Baru.
\end{abstract}

Keywords: Experiment, Jarimatika, Multiplication

\section{PENDAHULUAN}

Matematika adalah salah satu pembelajaran yang disiapkan pada masing-masing sekolah diseluruh jenjang pendidikan, semenjak dari tahap pendidikan sekolah dasar sampai perguruan tinggi. Pelajaran matematika merupakan keterampilan dasar yang harus dikuasai peserta didik sebelum mempelajari bahan ajar sains.(Afriani et al., 2019). Tujuan mempelajari matematika di sekolah adalah untuk pendirian perilaku peserta didik, memberikan dorongan pada kekuatan berfikir juga memberi dorongan pada keterampilan dalam penerapan matematika.(Alhaddad, 2015). 
Menurut (Nurmasari, 2011) Manfaat yang bisa diperoleh dari pembelajaran matematika antara lain: melatih berpikir secara logis dan sistematis, mengembangkan daya nalar, melatih memecahkan masalah yang ditemukan dalam kehidupapan sehari-hari, dan mempersiapkan siswa untuk menghadapi tantangan zaman yang selalu berubah. Berkaitan dengan hal-hal yang tertera di atas dapat disadari betapa pentingnya matematika dalam kehidupan maka tidak perlu diherankan lagi pembelajaran matematika mengalami perkembangan dari zaman ke zaman. Perkembangan matematika sering merintis kemungkinan penerapannya yang baru pada berbagai bidang ilmu lain.(Chasanah, 2020). Oleh karena itu pembelajaran matematika sangat penting dikuasai oleh siswa. Sebagai salah satu mata pelajaran yang harus dikuasai siswa pembelajaran matematika memiliki fungsi komunikasi yang dapat dimanfaatkan dalam kehidupan sehari-hari. Melalui mempelajari matematika peserta didik diharapkan mampu memiliki kompetensi yang cukup handal untuk mengimbangi bermacam-macam permasalah yang muncul di dalam kehidupan nyata.

Namun banyak siswa SD yang beranggapan bahwa matematika merupakan salah satu pelajaran yang sulit untuk dipelajari, hal ini karena matematika mengandung angka dan teori. matematika mengenai konsep dan abstrak maka guru sebagai tenaga pengajar memerlukan alat bantu berupa media atau alat peraga yang menarik sehingga memudahkan siswa untuk memahami materi yang telah disampaikan guru dan sukses dalam belajar matematika. Pembelajaran matematika sebaiknya dilaksanakan dengan menggunakan metode pembelajaran yang banyak melibatkan praktik mengerjakan soal latihan, agar siswa lebih terampil dalam menyelesaikan masalah serta bermanfaat dalam kehidupan sehari-hari.

Berkaitan dengan hal-hal yang tertera di atas dapat disadari betapa pentingnya matematika dalam kehidupan maka tidak perlu diherankan lagi pembelajaran matematika mengalami perkembangan dari zaman ke zaman. Perkembangan matematika sering merintis kemungkinan penerapannya yang baru pada berbagai bidang ilmu lain.(Chasanah, 2020).

Matematika dapat diperoleh melalui pendidikan formal dan pendidikan nonformal, pendidikan formal yaitu yang didapat dari lembaga pendidikan (sekolah SD, SMP, SMA). Dimana pendidikan di SD Pada kelas rendah, pembelajaran matematika ditekankan pada empat kemampuan berhitung dasar, yaitu kemampuan berhitung penjumlahan, pengurangan, perkalian dan pembagian. Empat kemapuan berhitung ini sangat penting untuk dikuasai sebagai bekal penguasaan materi selanjutnya di kelas yang lebih tinggi. Selain itu juga penting untuk dikuasai karena sering digunakan dalam kehidupan siswa sehari-hari. Menurut Nyimas Aisyah (Dewi et al., 2020) "Kemampuan berhitung merupakan salah satu kemampuan yang penting dalam kehidupan sehari-hari, dapat dikatakan bahwa semua aktivitas kehidupan manusia memerlukan kemampuan ini”.

Kemampuan berhitung merupakan kecakapan untuk menyelesaikan perhitungan dengan bilangan. Banyak dijumpai kesalahan hitung yang dilakukan peseta didik dalam mengerjakan soal-soal matematika. Hal ini mempengaruhi kemampuan siswa dalam menyelesaikan soalsoal matematika terdapat beberapa faktor yang mempengaruhi kemampuan berhitung anak yaitu faktor dari dalam diri anak dan faktor dari luar diri anak. Faktor dari luar diri anak seperti dari proses belajar mengajar yang dapat mempengaruhi rendahnya kemampuan berhitung anak, misalnya pembelajaran yang kurang menyenangkan, proses pembelajaran yang monoton, dan media pembelajaran yang kurang menarik sehingga membuat anak merasa bosan dan kurang bersemangat.(Dewi et al., 2020) 
Dalam suatu proses belajar mengajar ada dua unsur yang amat penting yaitu metode mengajar dan media pembelajaran. Pemilihan motode pembelajaran yang inovasi merupakan bentuk kreativitas guru dalam mengelola pembelajaran yang semula monoton, membosankan, menjenuhkan menuju pembelajaran yang aktif dan efektif. (Utami, 2018) "Metode pembelajaran yang sesuai akan menarik siswa, membuat siswa fokus dengan pembelajaran, meningkatkan keberhasilan belajar siswa". Dalam proses pembelajaran, metode memegang peranan penting dalam mencapai sebuah tujuan belajar.

Menurut (Nurafifah \& Nurhayati, 2019) Metode adalah cara yang digunakan untuk mengimplementasikan recana yang sudah disusun dalam kegiatan nyata agar tujuan yang telah disusun tercapai secara optimal. Penggunaan metode pembelajaran yang sesuai bisa meningkatkan rasa senang dan gembira bagi siswa dan memperbaiki semangat siswa dan dapat membantu guru dalam menyampaikan materi pembelajaran. (Utami, 2018) "Metode mengajar yang baik adalah metode mengajar yang sesuai dengan karakteristik siswa". Akan tetapi metode yang digunakan seringkali kurang efektif karena tidak sesuai dengan meteri atau karakteristik anak. Selain itu, hampir semua metode yang digunakan memerlukan alat bantu dan kadang membebani memori otak anak. Ditinjau dari karakteristik anak pada umumnya dikelas III SD sudah mampu menghitung penjumlahan dan pengurangan dengan mudah. Namun, dalam menghitung perkalian dan pembagian seringkali anak mengalami kesulitan.

Berdasarkan hasil observasi yang dilakukan di SDN 15 Koto Baru pada tanggal 04 Agustus sampai dengan 26 desember. Selama pengenalan lapangan persekolahan (PLP). Didapatkan permasalahan dalam pembelajaran pendidikan matematika. Yaitu siswa masih mengalami kesulitan dalam memahami dan mengerjakan soal-soal dalam materi perkalian. Hal ini terlihat dari beberapa soal matematika yang diberikan masih banyak siswa yang tidak bisa menjawab, kalaupun bisa menjawab tapi sangat lambat bahkan ada yang sampai salah jawaban. Masalah ini dikarenakan tidak semua siswa mempunyai daya ingat yang kuat untuk menghafalkan perkalian. Sehingga seringkali siswa lupa dan kesulitan dalam mengerjakan soal perkalian. Bahkan hanya sedikit siswa yang menguasai konsep perkalian dengan baik. Hal itu dilihat dari hasil penilaian harian $(\mathrm{PH})$ dan penilaian tengah semester (PTS) siswa yang masih dibawah KKM perhatikan tabel berikut.

Tabel 1. 1 data nilai ujian tengah semester kelas III SDN 15 Koto Baru Dharmasraya

\begin{tabular}{|c|c|c|c|c|}
\hline \multirow{2}{*}{ Jumlah Siswa } & \multicolumn{2}{|c|}{ Tuntas } & \multicolumn{2}{c|}{ Tidak Tuntas } \\
\cline { 2 - 5 } & Jumlah & $\%$ & Jumlah & $\%$ \\
\hline 20 & 10 & 50 & 10 & 50 \\
\hline
\end{tabular}

mata pelajaran matematika.

Sumber: buku penilaian guru

Berdasarkan analisis data di atas maka penulis memilih metode pembelajaran yang efektif dan cocok untuk meningkatkan kemampuan berhitung perkalian siswa dengan metode 
jarimatika. Metode jarimatika adalah teknik berhitung mudah dan menyenangkan dengan menggunakan jari tangan. Melalui jari-jari yang dimiliki manusia, baik di tangan kanan maupun tangan kiri memiliki fungsi yang penting, jari-jari tersebutlah yang digunakan siswa untuk belajar berhitung perkalian lebih cepat sehingga tidak tergantung pada kalkulator (Rahmawati, 2018).

Berdasarkan beberapa permasalah diatas maka penelitian tentang "Pengaruh Penerapan Metode Jarimataika Terhadap Kemampuan Berhitung Perkalian Siswa Kelas III Sekolah Dasar" penting untuk dilakukan.

\section{METODE PENELITIAN}

Penelitian ini adalah penelitian kuantitatif dengan menggunakan metode penelitian eksperimen. Penelitian eksperimen adalah suatu peneltian yang mencoba untuk mencari hubungan sebab akibat antara variabel bebas dengan variabel terikat, dimana variabel bebas sengaja dikendalikan dan dibedakan perlakuan (Jakni, 2016). Penulis menggunakan desain eksperimennya yaitu pre-experimental designs. Pre-experimental designs dikatakan belum eksperimen sungguh-sungguh, karena masih terdapat variabel luar yang ikut berpengaruh terhadap terbentuknya variabel dependen. Maka, hasil eksperimen yang merupakan variabel dependen itu bukan semata-mata dipengaruhi oleh variabel independen. Hal ini dapat terjadi, karena tidak adanya variabel kontrol dan sampel tidak dipilih secara random (acak) (Sugiyono, 2017).

Dalam pre-experimental desings penulis menggunakan bentuk one grup pretes-posttest design. One grup pretes-posttest design menggunakan satu kelas untuk penelitian serta menggunakan pre-test sebelum diberikan perlakuan (treatment) sehingga hasil perlakuan dapat diketahui dengan akurat, karena membandingkan dengan keadaan sebelum diberikan perlakuan. Alasan menggunakan One grup pretes-posttest design karena saat melakukan penelitian menggunakan satu kelas.

\section{HASIL DAN PEMBAHASAN}

Berdasarkan hasil observasi siswa kelas III SDN 15 Koto baru yang berjumlah 20 peserta didik, diperoleh bahwa siswa terlihat kurang pandai dalam perkalian 13 siswa, siswa yang lancar perkalian 7 siswa. Selanjutnya, siswa kelas III SDN 15 Koto baru. berdasarkan banyaknya peserta didik yang kurang pandai dalam perkalian maka dilakukan penelitian menggunakan metode jarimatika diharapkan dapat menjadikan siswa lancar dalam perkalian.

Sebelum dilaksanakan penelitian di sekolah SDN 15 Koto Baru. Peneliti melakukan uji coba 30 soal pilihan ganda di SDN 02 TIMPEH. Kemudian dianalisis menggunakan microsoft excel, hasil dari uji validilitas terdapat 10 soal tidak valid dan 20 soal valid. Selanjutnya diuji reliabilitas yang hasilnya soal reliabel. Soal diuji daya beda yang hasilnya 10 soal katagori jelek dan 20 soal katagori baik. Terakhir soal diuji tingkat kesukarannya yang hasilnya 19 soal katagori mudah dan 11 soal kategori sedang. Jadi , 10 soal yang dibuang 20 soal yang digunakan untuk penelitian.

Pada langkah pertama peneliti yaitu peneliti memberikan soal pretest kepada siswa. Sebagaimana pada hasil pretest hanya 4 orang siswa yang mencapai kriteria ketuntasan minimal (KKM) 71, dimana rata-rata kelas hanya 58. Hasil tersebut dapat dinyatakan masih rendah karena belum mencapai KKM. Selain itu, hasil tersebut menunjukan adanya masalah 
pada proses pembelajaran sehingga berdampak pada hasil belajar siswa yang belum maksimal. Hasil belajar merupakan kemampuan yang dicapai siswa dari proses belajar yang dapat diketahui dari pencapaian saat melakukan serangkaian tes hasil belajar.

Selanjutnya, peneliti menggunakan treatment (perlakuan) yang dilaksanakan sebanyak 4 kali pertemuan yang dapat dijelaskan pada tabel dibawah ini:

\begin{tabular}{|c|c|c|c|}
\hline No & Pertemuan & Pembelajaran & Hari/Tanggal \\
\hline 1. & Ke-1 & Operasi perkalian & Rabu/14 Juli 2021 \\
\hline 2. & Ke-2 & $\begin{array}{c}\text { Operasi perkalian menggunakan } \\
\text { jarimatika }\end{array}$ & Kamis/15 Juli 2021 \\
\hline 3. & Ke-3 & $\begin{array}{c}\text { Operasi perkalian menggunakan } \\
\text { jarimatika }\end{array}$ & Jumat/16 Juli 2021 \\
\hline 4. & Ke-4 & $\begin{array}{c}\text { Operasi perkalian mengginakan } \\
\text { jarimatika }\end{array}$ & Senin/19 Juli 2021 \\
\hline
\end{tabular}

Pelaksanaan treatment (perlakuan) dilaksanakan sesuai dengan RPP yang dapat dilihat pada lampiran 12. Setelah pemberian treatment (perlakuan), selanjutnya peneliti memberikan soal posttest kepada siswa. Hasil posttest menunjukan adanya peningkatan hasil belajar siswa, dimana rata-rata kelas mencapai angka 83,25. Selain itu, semua siswa mencapai ketuntasan, dimana hasil yang diperoleh sangat baik, nilai tertinggi mencapai angka 100 dan nilai terendah yaitu 65 .

Usai dilaksanakan penelitian di kelas III SDN 15 Koto Baru diperoleh data pretest dan posttest. Setelah itu data pretest dan posttest di uji noralitasnya. Hasil uji normalitas data pretest dan posttest memperoleh signifikansi data pretest yaitu $0,262<0,05$ dan signifikansi yang diperoleh dari data posttest yaitu $0,580>0,05$, yang artinya data pretest dan posttest berdistribusi normal.

Berdasarkan deskripsi data hasil penelitian data hasil analisis pretest dan postest, dengan menggunakan uji Paired Sample tes menunjukkan nilai signifikasi $0,000<0,05$ maka hasil uji Paired sample tes dapat disimpulkan bahwa $\mathrm{H}_{0}$ ditolak dan $\mathrm{H}_{\mathrm{a}}$ diterima. Dengan diterimanya $\mathrm{H}_{\mathrm{a}}$ pada pengujian hipotesis tersebut, maka dapat disimpulkan bahwa penelitian ini dapat menguji kebenaran hipotesis yaitu terhadap peningkatan kemampuan dalam perkalian anatara sebelum dan sesudah diterapkannya metode jarimatika pada kelas III SDN 15 Koto Baru.

\section{SIMPULAN}

Berdasarkan hasil penelitian untuk mengetahui pengaruh metode jarimatika terhadap kemampuan berhitung perkalian siswa kelas III SDN 15 Koto Baru dapat ditarik kesimpulan. Bahwa, Tes hipotesis menunjukkan terdapat perbedaan antara nilai siswa sebelum diberikan perlakuan atau pretest dengan nilai setelah diberikan perlakuan atau posttest. Dengan demikian dapat dikatakan terdapat pengaruh yang signifikan dalam penggunaan metode jarimatika terhadap hasil belajar pada mata pelajaran Matematika kelas III SDN 15 Koto Baru, Dharmasraya 


\section{DAFTAR RUJUKAN}

Afriani, D., Fardila, A., \& Septian, D. G. (2019). Penggunaan Metode Jarimatika Dalam Meningkatkan Kemampuan Berhitung Perkalian Pada Siswa Sekolah Dasar. Of Elementary Education, 02(05), 191-196.

Alhaddad, I. (2015). Perkembangan Pembelajaran Matematika Masa Kini. Matematika Dan Pendidikan Matematika, 4(1), 13-26.

Chasanah, M. Z. (2020). Pengaruh Penerapan Metode Jarimatika Terhadapa Kemampuan Berhitung Perkalian Siswa Kelas III di Madrasah Ibtidaiyah Negeri 2 Ponorogo Tahun Akademik 2019/2020.

Dewi, V. F., Suryani, Y., \& Hidayat, S. (2020). Pengaruh Penggunaan Jarimatika Terhadap Kemampuan Berhitung Perkalian Peserta Didik Kelas IV Sekolah Dasar. Jurnal Pendidikan Dasar, 2(2), 79-87.

Jakni. (2016). Metodologi Penelitian Eksperimen Bidang Pendidikan. Alfabeta.

Nurafifah, I. H., \& Nurhayati, T. (2019). Pengaruh Pengunaan Metode Jarimatika Terhadap Hasil Belajar Matematika di Kelas III B MI Negeri 6 Kuningan Kabupaten Kuningan. Of Elementary Education, 1(1), 1-16.

Nurmasari, L. (2011). Peningkatan Kemampuan Menghitung Perkalian Melalui Metode Jarimatika pada Kelas II SD Negeri 3 Pringanom Sragen Tahun Pelajaran 2010/2011.

Rahmawati, Y. D. (2018). Pengaruh Metode Jarimatika Terhadap Motivasi dan Hasil Belajar Matematika Operasi Perkalian pada Siswa Kelas III MI Tarbiatul Islamiah Noborejo Salatiga Tahun Pelajaran 2017/2018.

Sugiyono. (2017). Metode Penelitian Kuantitatif, Kualitatif, dan R\&D. Alfabeta.

Utami, N. A. T. (2018). Pengaruh Metode Jarimatika Terhadap Hasil Belajar Perkalian. Jurnal Pendidikan Guru Sekolah Dasar Edisi 32 Tahun Ke-7 2018, 3.196(6-8), 1-9. 